\title{
«ЗАДАЧИ НА СМЫСЛ॥: ДИАЛОГОВЫЕ ФОРМЫ И УСЛОВИЯ ИСПОЛЬЗОВАНИЯ В УЧЕБНОМ ПРОЦЕССЕ
}

\author{
Белова Елена Владимировна \\ Лукьяненко Марина Алексеевна
}

«Задачи на смысл» могут обладать значительным дидактическим ресурсом в обеспечении прочессов осознания смысловых связей и отношений между учебным содержанием и обучающимися. Они могут рассматриваться как дидактические технологии по инициации смыслообразования обучаемых. Для разработки системы по использованию «задач на смысл» в практике учебного процесса необходимо выявить особенности их реализации в рамках межличностного диалога. Особенности реализации «задач на смысл» в диалоговом режиме как раз и представлены в данной статье.

Ключевые слова: смыслообразование, дидактические технологии, инициации, развитие, «задачи на смысл», смысловая срера личности.

\section{"SENSE TASKS": DIALOGUE FORMS AND CONDITIONS OF USE IN THE EDUCATIONAL PROCESS}

\author{
Belova Elena Vladimirovna \\ Luk'ianenko Marina Alekseevna
}

"Sense tasks" can have a considerable didactic resource in supporting processes of comprehension of sense connections and relations between the educational content and learners. They can be considered as didactic technologies of learners' sense-creation initiation. For the development of the system of using "sense tasks" in the practice of the educational process it is necessary to reveal features of their realization within the limits of interpersonal dialogue. This article brings forward features of realization of "sense tasks" in a dialogue mode.

Keywords: sense-creation, didactic technologies, initiations, development, "sense tasks", sense sphere of personality.

В современной психолого-педагогической науке разрабатываются особые дидактические технологии, призванные инициировать смыслообразование обучаемых. Они необходимы для выведения учебного процесса на личностносмысловой уровень, непосредственно влияющий на особенности смыслообразования и смысловыявления учащихся как компонентов индивидуальной 
мотивационно-смысловой сферы личности обучаемого. При этом содержание и технологии оказываются взаимосвязанными: если содержание «питает» развитие личности, ее смысловые структуры, то технологии включают, запускают механизм развития. Технологии обучения предстают как механизм самореализации содержания (И. В. Абакумова, П. Н. Ермаков) [1].

Наиболее часто в реальной практике учебного процесса такие дидактические технологии реализуются в форме задач, которые решают не на уровне устранения логического противоречия, а на уровне раскрытия того смысла, который возникает у познающего в процессе освоения изучаемого содержания. Добавочный (смысловой) компонент обогащает содержание задачи. Такие задачи называют «задачами на смысл» (В. М. Голубова, М. В. Гудкова, М. Ю. Коноваленко, И. Е. Нестеренко, И. А. Рудакова, В. А. Сластенин, В. Я. Ступаков, Е. Д. Файзуллаева, В. Т. Фоменко). В учебном процессе «задачи на смысл» актуализируют личностный смысл обучаемого и способствуют его переходу на более высокий уровень - уровень смысловой регуляции жизнедеятельности (как способ связи человека с миром), что свидетельствует о высоком дидактическом и воспитательном потенциале этого класса задач. Педагог, использующий этот тип задач для поддержки обучающегося, предусматривает перевод неопределенных ситуаций в личностно-значимые, выбор специфических методов обучения, разработку учебных заданий личностно-развивающей направленности и создание комфортной образовательной среды для обеспечения постановки смысла цели задачи, ее принятия и переосмысления.

В работах В. А. Савина (2013) предложена модель операционализации технологий использования такого рода задач в учебном процессе. По его мнению, эти задачи должны создавать ситуацию смысловой неопределенности, которая, в свою очередь, станет катализатором непосредственного смыслообразования - «учитель создает ситуацию "смысловой неопределенности" или "смыслового диссонанса" и предлагает им самим найти способ его разрешения; сталкивает противоречия практической деятельности (например, показано заведомо спорное женское лицо и учитель утверждает: “Это настоящая красавица, хотите быть на нее похожими и почему?"); излагает различные точки зрения на один и тот же вопрос; предлагает экспериментальной группе рассмотреть ситуации с различных (альтернативных) позиций; побуждает старшеклассников делать сравнения, обобщения, выводы из ситуации, сопоставлять факты; ставит конкретные вопросы (на обобщение, обоснования, конкретизацию, обоснование логики рассуждения); ставит проблемные задачи (с недостаточными или избыточными исходными данными, с неопределенностью в постановке вопроса, с противоречивыми данными, с заведомо допущенными ошибками, 
с ограниченным временем решения, на преодоление психической инерции и т. д.)» [7]. Предложенная последовательность действий педагога достаточно универсальна, она может быть использована для разного типа «задач на смысл». А в современной психологии и педагогике уже существует несколько таких типологий. По мнению В. А. Савина, в учебном процессе можно успешно применять задачи, связанные с самоидентификацией; задачи, ориентированные на ситуации неопределенности; задачи в форме альтернативного позиционирования; задачи, преобразующие стимульную мотивацию в смыслообразующую.

По мнению другого современного исследователя Н. Ю. Зильбербранд (2013), анализирующую этот тип задач с точки зрения смысловой насыщенности, «задачи на смысл» можно типологизировать по следующим основаниям:

- по критерию «источники их постановки» выделяются деятельностнотворческий и мотивационно-коммуникативный блоки смысловых задач. Смысловая составляющая раскрывается субъектной позицией, личностными детерминантами, ценностями познания и отношения, поиском смысла и др.;

- по критерию «характер смысловых связей» четыре типа задач (аффективносмысловые, интенционально-смысловые, задачи на самоосуществление и рефлексивно-смысловые) обеспечивают равномерность развития смысловой сферы, гармонизацию процессов смыслоосознания и переосмысления обучающихся.

Однако в предлагаемых дидактических типологиях по использованию «задач на смысл» как технологий инициации смыслообразования обучающихся не рассматривается очень важный компонент - диалогическая составляющая при применении задачи. Учебный межличностный диалог это основа любой технологии, ориентированной на смысловое развитие обучаемых. Межличностный диалог как технология, использующая «задачи на смысл», должен употребляться для развития мотивационно-смысловой сферы обучаемых при условии детальной проработки диалогового поля как пространства смыслообразования в учебном процессе и целостной иерархии видов, компонентов и уровней его учебной технологичности. Такой диалог предполагает обращение учителя непосредственно к ценностно-значимому для учащихся опыту, к жизненному миру обучаемого через актуализацию личностного смысла, смысловых установок, мотивов. В результате происходит направленная трансформация смыслов партнеров, в качестве которых выступают учитель и ученик, в направлении их сближения происходит процесс смыслового взаимодействия. Именно в этом ракурсе и можно осмыслить специфику «задач на смысл» в условиях диалогового взаимодействия 
«учитель - ученик». В ходе решения «задачи на смысл» происходит внутренняя работа личности по соотнесению проявлений мотива в нескольких пересекающихся друг с другом плоскостях: в отношении мотива к преодолеваемым личностью ради его достижения внешним и внутренним преградам; по сопоставлению мотива с другими выступающими в сознании субъекта возможными мотивами той же деятельности; по оцениванию мотива в его отношении к принятым личностью нормам и идеалам; по соотнесению мотива с реальными с точки зрения личности ее возможностями, т. е. с воспринимаемым образом Я; по сравнению собственного мотива с предполагаемыми мотивами других субъектов.

Диалоговая составляющая в «задачах на смысл» как дидактических технологиях берет на себя функцию активатора, запускающего «поток сознания» по поиску того, что выводит постигаемое учебное содержание на уровень личностно-смыслового принятия. Смыслопорождающий диалог оживляет «задачи на смысл», выводит их содержание на уровень субъективного присвоения содержания. И именно поэтому его необходимо рассматривать не как отдельный методический прием или способ, решающий частнопредметную задачу, а как нечто процессуально-целостное, воспроизводимое в других дидактических условиях и, самое главное, дающее устойчивый желаемый результат. По мнению ряда авторов (И. В. Абакумова, В. Т. Фоменко, В. В. Суфиянов) диалог как педагогическая технология вводится в качестве модели целостной технологии процесса в континууме от микродиалога (диалоги «учитель - ученик», «ученик - ученик») до макродиалога (диалог культур) в границах диалогового поля как пространства смыслообразования в учебном контексте. Границы диалогового пространства рассматриваются как система психолого-педагогических оснований диалога, пространство для существования личностных атрибутов как межличностных, и фиксируют условия, при которых возможно бытие личности не в ущерб со-бытию с другими.

Система операционализации «задач на смысл» в условиях межличностного диалога включает следующие компоненты:

- коммуникатор-учитель (тот, кто задает смысловую направленность диалога, ставит перед обучаемым «задачу на смысл», создает соответствующую смысловую установку или является транслятором определенного смысла);

- мотив и цель смыслообразования (то, что должно в диалоге порождать желание обучаемого вербализовать личностный смысл, отрефлексировать свои оценочные позиции);

- содержание (потенциальное поле «кристаллизации» смыслов);

- код коммуникации (устный или письменный диалог);

- реципиент-ученик (его мотивационно-смысловые особенности, готовность раскрывать смысл постигаемого); 
- результат в виде смыслового следа как предпосылки смысловой установки раскрывать смысловые интенции на последующих этапах познания (обратная связь, выявляющая особенности смыслообразования в данном диалоге).

В качестве основных условий для того, чтобы «задачи на смысл» действительно инициировали смыслообразование обучаемых, можно выделить следующие:

- необходимость отказа от информационного давления, от авторитарных оценок, морализаторства;

- понимание реальных потребностей и интересов обучаемых;

- освещение проблем в разных ракурсах, позитивная установка на разрешение противоречий, информационная новизна;

- право обучаемого на собственные оценки (аутентичность личности).

В практику учебного процесса может быть введена психологодидактическая типология межличностного диалога как технологии, инициирующей смыслообразование с использованием «задач на смысл» разной смысловой насыщенности:

- диалог-истолкование (ориентирован на постижение значений тех или иных понятий на рациональном уровне в результате объяснения и вопросов учителя);

- диалог-включенность (с использованием контекста, аналогичного реальным жизненным ситуациям, характерным для данной возрастной группы учащихся, от реального субъективного опыта - к субъектному жизненному миру, через раскрытие личностных смыслов данного контекста, трансформацию смыслов в совместной деятельности);

- диалог-проникновение (учебная коммуникация как направленная трансляция смыслов определенных содержательных фрагментов постигаемой информации, инициация смыслообразования учащихся преподавателем);

- диалог-переживание (выведение диалога на смысловой уровень, попытка создания общего - «учитель - ученик» - смыслового пространства, формирование более сложных смысловых конструктов как компонентов смысложизненных ориентаций личности).

В соответствии с этой типологией межличностных диалогов в учебном процессе возможно разработать и «задачи на смысл», которые будут соответствовать определенному уровню (силе) смысловых инициаций со стороны педагога. Диалог как переживание, через передачу опыта как совместно пережитого знания, может характеризоваться следующими базовыми составляющими:

- разотождествление смысловых отношений (разделение Я и Мое, через актуализацию Я); 
- полимодальная смысловая презентация (составляющая, направленная на организацию одновременной представленности сознанию двух или больших отношений);

- выявление уровня смысловой насыщенности (составляющая, инициирующая осознание факта пересечения жизненных отношений);

- структурирование (составляющая, направленная на обнаружение или установление разного рода связей между жизненными отношениями).

В условиях личностного присвоения учебного содержания, характеризуемого разнообразием смыслов и смысловых оттенков, в их неоднозначном, сложном, хаотическом и вместе с тем целостном взаимодействии имеется вероятность того, что посредством «задач на смысл» субъектный опыт конкретно данного обучаемого “откликнется» на что-нибудь в окружающем его смысловом множестве, соединится с его отдельными фрагментами, отреагирует на него в целом.

В процессе познания, в той или иной степени управляемом преподавателем, «задачи на смысл» дают возможность через диалог задать поле определенной смысловой насыщенности, и именно благодаря этому и возникает внутри личности обучаемого «созвучие двух ее образов» [3], пересечение зоны ближайшего развития личности и диалогового поля, инициируется «смысловая сингулярность» [1]. Именно этот момент дает познающему ощущение внутренней согласованности, узнавания себя и своих ценностей, осмысленности; понимание познаваемого как совместно осваиваемого. «Человек выбирает не один из двух предметов или даже мотивов. Он выбирает себя. Выбор изменяет его личность. Парадоксально выражаясь, не столько личность делает выбор, сколько выбор делает личность, формирует ее» [3]. Таким образом, умение использовать «задачи на смысл» как технологии инициации смыслообразования становится механизмом актуализации смыслового выбора и смыслового предпочтения обучаемых в учебном процессе.

\section{Литература}

1. Абакумова И. В., Ермаков П. Н. Смыслодидактика:учебник для магистров психологии и педагогики. - М.: КРЕДО, 2010. - 386 с.

2. Абакумова И. В., Кагермазова Л. Ц., Савин В. А. Диалог культур как смыслотехнология формирования установок толерантного сознания и поведения студентов вуза // Российский психологический журнал. 2013. - Т. 10. - № 1. - С. 46-59.

3. Василюк Ф. Е. Понимающая психотерапия как психотехническая система // Московская психологическая школа: История и современность: в 4 т. Том 4 / Под общ. ред. действ. чл. РАО, проф. В. В. Рубцова. - М.: Изд-во МГППУ, 2007. - С. 45-61. 
4. Зильбербранд Н. Ю. Дидактическая сущность смысловых задач // Вестник Череповецкого государственного университета. - 2013. - Т. 2. № 4 (52). - С. 106-109.

5. Зильбербранд Н. Ю., Рудакова И. А. Типология смысловых задач в современной дидактике // Фундаментальные исследования. Педагогические науки. - 2014. - № 5. - С. 177-181.

6. Савин В. А. Дидактические основы развития самопрезентации как компонента профессиональной успешности будущего специалиста // Российский психологический журнал. - 2012. - Т. 9. - № 2. - С. 55-61.

7. Савин В. А. Методическая программа реализации модели развития готовности старшеклассников к самопрезентации: для учителей и школьных психологов. - М.: КРЕДО, 2013. - 26 с.

8. Суфиянов В. В. Диалог как педагогическая технология в смыслообразующем учебном контексте: автореф. дис. ... канд. пед. наук. - Ростов н/Д, 2007. -23 c.

\section{References}

1. Abakumova I. V., Ermakov P. N. Smyslodidaktika: uchebnik dlia magistrov psikhologii i pedagogiki [Sense didactics: textbook for master students in psychology and pedagogics]. Moscow, KREDO Publ., 2010. 386 p.

2. Abakumova I. V., Kagermazova L. Ts., Savin V. A. Dialog kul'tur kak smyslotekhnologiia formirovaniia ustanovok tolerantnogo soznaniia i povedeniia studentov vuza [The dialogue of cultures as a sense technology of forming attitudes of tolerant consciousness and behavior of students of the institute of higher education]. Rossiiskii psikhologicheskii zhurnal Russian Psychological Journal, 2013, V. 10, no. 1, pp. 46-59.

3. Vasiliuk F. E. Ponimaiushchaia psikhoterapiia kak psikhotekhnicheskaia Sistema. Moskovskaia psikhologicheskaia shkola: Istoriia i sovremennost': $v 4 t$. [Understanding psychotherapy as a psychotechnical system. Moscow psychological school: the history and the present. In 4 volumes. Volume 4]. Moscow, Moscow State Psychological-Pedagogical University Publ., 2007, pp. 45-61.

4. Zil'berbrand N. lu. Didakticheskaia sushchnost'smyslovykh zadach [Didactic essence of sense problems]. Vestnik Cherepovetskogo gosudarstvennogo universiteta - Cherepovets State University Bulletin, 2013, V. 2, no. 4 (52), pp. 106-109.

5. Zil'berbrand N. lu., Rudakova I. A. Tipologiia smyslovykh zadach $v$ sovremennoi didaktike [The typology of sense problems in modern didactics]. Fundamental'nye issledovaniia. Pedagogicheskie nauki - Basic Research. Pedagogical Sciences, 2014, no. 5, pp. 177-181. 
6. Savin V. A. Didakticheskie osnovy razvitiia samoprezentatsii kak komponenta professional'noi uspeshnosti budushchego spetsialista [Didactic bases of the development of self-presentation as a component of professional success of the future expert]. Rossiiskii psikhologicheskii zhurnal - Russian Psychological Journal, 2012, V. 9, no. 2, pp. 55-61.

7. Savin V. A. Metodicheskaia programma realizatsii modeli razvitiia gotovnosti starsheklassnikov k samoprezentatsii: dlia uchitelei i shkol'nykh psikhologov [Methodical program of implementing the model of the development of senior pupils' willingness to present themselves: for teachers and school psychologists]. Moscow, KREDO Publ., 2013. 26 p.

8. SufiianovV.V.Dialogkakpedagogicheskaiatekhnologiiavsmysloobrazuiushchem uchebnom kontekste. Diss. cand. ped. nauk [Dialogue as a pedagogical technology in the sense-creating educational context. Cand. ped. sci. diss]. Rostov-on-Don, 2007. 23 p. 